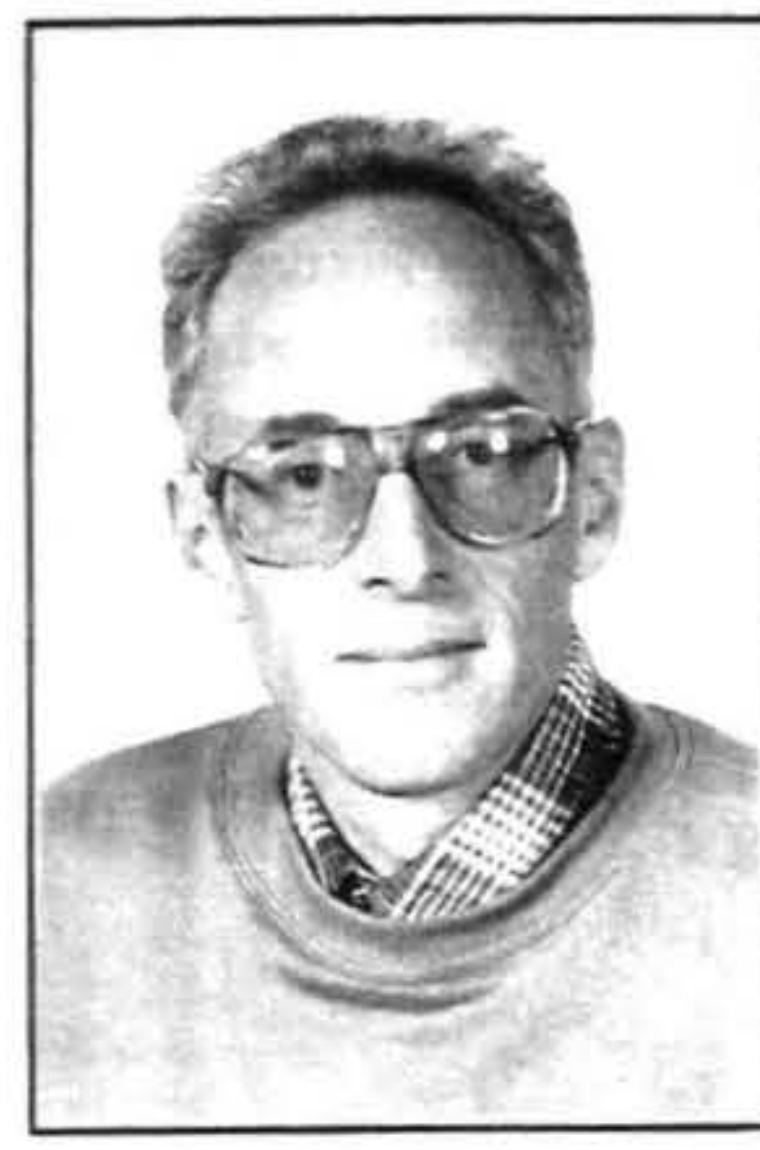

\title{
UNEMPLOYMENT DYNAMICS IN NEW ZEALAND 1985-1994
}

\author{
Brian Silverstone and Susi Gorbey \\ University of Waikato and NZIER
}

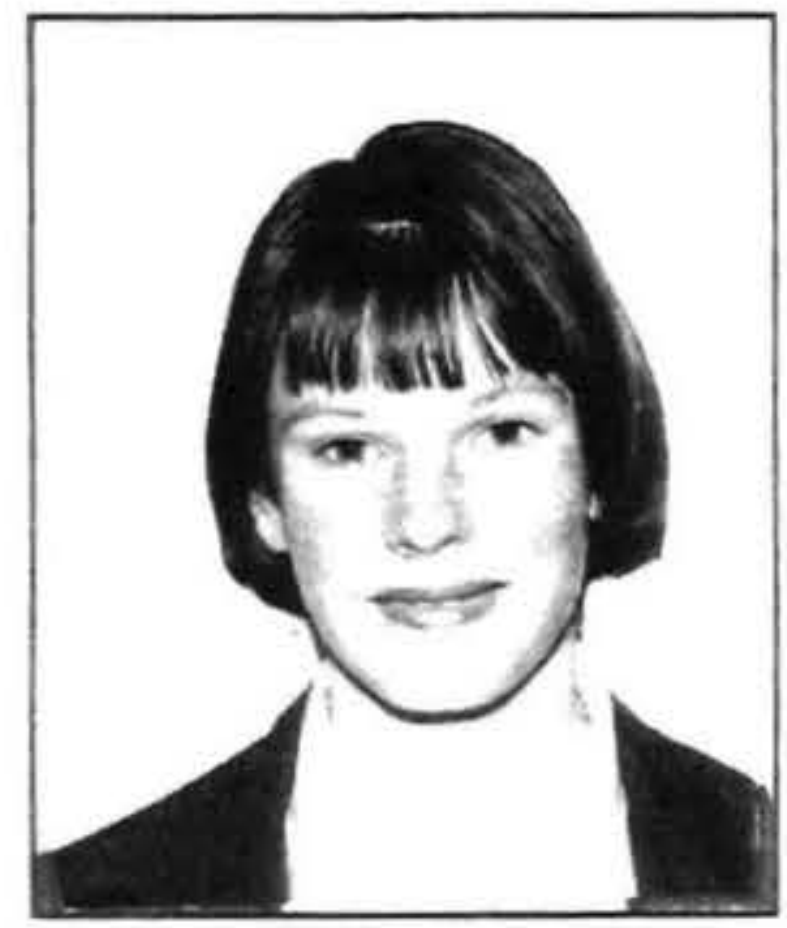

\begin{abstract}
The quarterly change in the number of unemployed New Zealanders is usually quite small relative to the total number of people unemployed. For the year ended September 1994, for example, the absolute average quarterly change in Household Labour Force Survey (HLFS) unemployment was 10,500 people against a quarterly average unemployment pool of 145,000 people. These relatively small stock changes, however, conceal the much larger flows into and out of unemployment of possibly 70,000 people during each quarter of 1993/94. The scale of these flows, and the associated probabilities of entering and leaving unemployment, are not widely known. Using data from the HLFS, this paper updates and extends the relatively small amount of New Zealand research on labour market dynamics. It begins with a definition and data on the unemployment stock-flow relationship in New Zealand. This isfollowed by a brief analysis of the flows between the major labour market states and the associated flow rates and cycles. The paper will indicate how gross flows data can be used to give insights into gender and age differences in unemployment and 'steady-state' outcomes. The accuracy of gross flows data and the formal modelling of unemployment inflows and outflows are ongoing projects.
\end{abstract}

The quarter-by-quarter change in the number of New Zealanders who are unemployed is usually quite small compared to the total number of people unemployed. For the year ended September 1994, for example, the absolute average quarterly change in surveyed unemployment was 10,500 people compared to a quarterly average unemployment pool of 145,000 people. This net change - historically relatively high - conceals the much larger gross flows into and out of unemployment of possibly 70,000 people during each quarter of 1993/94. Furthermore, it is estimated that during the year ended September 1994, on average, for every 100 people who were unemployed in the previous quarter, around 27 had become employed by the next quarter, 28 had left the labour force while 45 people remained unemployed.

The scale of these flows, and the associated probabilities of entering and leaving unemployment, are not widely known. Using data from the Household Labour Force Survey (HLFS) this paper contributes to the recent New Zealand research on labour market dynamics. (See, for example, Grimmond 1993, Silverstone 1993 and Woolf 1989.) It begins with a definition and data on the unemployment stock-flow relationship in New Zealand. This is followed by a brief analysis of the flows between the major labour market states and the associated flow rates and cycles with particular reference to unemployment. Finally, we look at some extensions to the basic analysis and directions for further research.

\section{Definition and data}

By definition, the number of people unemployed in the current period $(U)$ is equal to the number unemployed in the previous period $\left(U_{-1}\right)$ plus current inflows to unemployment (I) minus current outflows (O), that is,

$$
\mathrm{U}=\mathrm{U}_{-1}+\mathrm{I}-\mathrm{O}
$$

In several countries, including New Zealand, information about labour market inflows and outflows is obtained from panel surveys. In the typical survey, households are interviewed over consecutive months or quarters and then rotated out of the survey. Participation in adjacent surveys enables households to be matched between months or quarters and their labour market status tracked. Since December 1985, Statistics New Zealand has published a Household Labour Force Survey. Currently some 32,000 people in 16,000 households are interviewed quarterly. Households remain with the survey for eight consecutive quarters. Each quarter, one eighth of the households are rotated out of the survey and replaced by a new sample of households. As a result, seven-eighths of surveyed households are, in principle, common to adjacent surveys. In practice, due to such factors as households shifting and deaths, just three quarters of households are usually common to adjacent surveys. (For the year ended September 1994 , households common to adjacent surveys fell tempo- 
rarily to about 67 percent of the population due to a redesigned sample).

Between quarters, an individual will experience at least one of nine possible labour market flows. The HLFS, however, can record just one flow for each individual. Three of these flows reflect an unchanged status (namely, continuing employment (EE), unemployment (UU) or not in the labour force (NN)). Six flows reflect changes between these states, for example, from employment to unemployment (EU). At any time, though, an individual isclassified as either employed (E), unemployed (U) or not in the labour force $(\mathrm{N})$.

Table 1 is a matrix of the nine labour market states where the abbreviations indicate a particular flow. EU, for example, is an abbreviation for $\mathrm{E}_{-1} \rightarrow \mathrm{U}$. It indicates the number of workers who were employed in the previous quarter (the origin state, denoted by $\mathrm{E}_{-1}$ ) who are now unemployed in the current quarter (the destination state, denoted by $U$ ). The same reasoning applies to the remaining entries. The sum of the $\mathrm{E}, \mathrm{U}$ and $\mathrm{N}$ columns gives the respective labour market totals for the current quarter, while the sum of the rows gives the totals for the previous quarter.
September 1994. The entries in Table 2 and in Figure 1 are the quantitative counterpart to the elements in Table 1.

Substituting the data from Table 2 (or from Figure 1) into equation 2 gives the average quarterly change in New Zealand's unemployment for the year ended September $1994(-6,200)$ in terms of inflows $(42,600)$ and outflows $(48,800)$, that is:

$$
\begin{aligned}
83.1 & =89.3+(16.9+25.7)-(24.3+24.5) \\
& =89.3+42.6-48.8 \\
-6.2 \quad & =42.6-48.8
\end{aligned}
$$

or

While the net quarterly change in unemployment during $1993 / 94$ was around 6000 people, this was the outcome of gross flows into and out of unemployment of around 43,000 and 49,000 people, respectively. As the gross flows measure of unemployment was about 83,000 people, these quarterly inflows and outflows were therefore equivalent to about 50 percent of the unemployment pool. Furthermore, as these gross flows are a sample of the HLFS population (as noted in Table 2) they should, in

\begin{tabular}{|c|c|c|c|c|}
\hline \multirow{2}{*}{$\begin{array}{l}\text { Labour Force Status } \\
\text { in Previous Quarter }\end{array}$} & \multicolumn{3}{|c|}{ Labour Force Status in Current Quarter } & \multirow[t]{2}{*}{ Row Totals } \\
\hline & $\mathrm{E}$ & $\mathrm{U}$ & $\mathbf{N}$ & \\
\hline E & $\mathrm{E}_{-1} \rightarrow \mathrm{E}$ & EU & EN & $\mathrm{E}_{-1}$ \\
\hline $\mathrm{U}$ & UE & UU & UN & $\mathrm{U}_{-1}$ \\
\hline $\mathbf{N}$ & NE & NU & NN & $\mathrm{N}_{-1}$ \\
\hline Column Totals & $\mathrm{E}$ & $\mathrm{U}$ & $\mathbf{N}$ & $w s=\Sigma$ colum \\
\hline
\end{tabular}
principle, be rated up to the HLFS population, by around

Table 1. Matrix of gross labour market flows

Using the entries in Table 1, equation 1 can be rewritten as:

$$
\begin{aligned}
U & =U_{-1}+I-O \\
& =U_{-1}+(E U+N U)-(U E+U N)
\end{aligned}
$$

or $\Delta \mathrm{U}=\mathrm{I}-\mathrm{O}$

where:

EU = inflow into unemployment from quits, layoffs and redundancies

NU = inflow into unemployment from outside the labour force

UE =outflow from unemployment to new hires and recalls

UN = outflow from unemployment to out of the labour force $=$ current quarter change in unemployment.

Table 2 and Figure 1 show the quarterly average of New Zealand's nine labour market flows for the year ended
60 percent. This would raise the average unemployment flows towards 70,000 people each quarter. As will be noted presently, however, the rating up of gross flows may represent an overstatement of the actual flows due to classification errors and missing observations.

Figure 1 and Table 2 highlight the substantial flows to and from the group classified as 'not in the labour force'. This is the population of working age who are 'nonparticipants' due, for example, to retirement, chronic illness, unpaid housework or child care, further education, unavailability, discouragement or voluntary nonparticipation. For much of the period since 1985, the rise in New Zealand's unemployment (and fall in employment) was, according to the flows approach, determined largely by movements to and from 'not in the labour force'. The increase in unemployment to $1991 / 92$ was not due, on balance, to an excess of layoffs and redundancies (EU) over new hires and recalls (EU). Indeed, even during the depths of New Zealand's recent depression, it was 'business as usual' for 
Table 2. Gross labour market flows

New Zealand, all ages, males and females, quarterly average 1993:3-1994:3 (thousands)

\begin{tabular}{|c|c|c|c|c|}
\hline \multirow{2}{*}{$\begin{array}{l}\text { Labour Force Status } \\
\text { in Previous Quarter }\end{array}$} & \multicolumn{3}{|c|}{ Labour Force Status in Current Quarter } & \multirow[t]{2}{*}{ Row Totals } \\
\hline & $\mathbf{E}$ & $\mathrm{U}$ & $\mathbf{N}$ & \\
\hline $\mathrm{E}_{-1}$ & 926.1 & 16.9 & 43.9 & 986.9 \\
\hline $\mathrm{U}_{-1}$ & 24.3 & 40.5 & 24.5 & 89.3 \\
\hline $\mathrm{N}_{-1}$ & 44.5 & 25.7 & 558.1 & 628.3 \\
\hline Column Totals & 994.9 & 83.1 & 626.5 & 1704.5 \\
\hline
\end{tabular}

Note: The column totals for E, $\mathrm{U}$ and $\mathrm{N}$ represent approximately 67,60 and 65 percent, respectively, of HLFS employment, unemployment and not in the labour force. Source: Statistics New Zealand, Household Labour Force Survey, Gross Flows.

many firms: the flows from unemployment to employment (UE) were, on average, consistently larger than the flows from employment to unemployment (EU). This leaves the flows to 'nonparticipation' as a major influence on the size and rate of unemployment in New Zealand. (See Blanchard and Diamond 1990 and Burda and Wyplosz 1994 for an account of similar experiences in other countries).

With respect to the 1993/94 year in particular, it is interesting to note that retirements and withdrawals from employment and unemployment into nonparticipation (EN and UN, respectively) were significantly greater than quits, layoffs and redundancies (EU). Similarly, new hires and recalls to employment from unemployment (UE) were just over half the entrants and re-entrants from 'not in the labour force' to employment (NE). Overall, these labour market dynamics reinforce the pivotal role of 'nonparticipation' for employment and unemployment outcomes in New Zealand.

For a longer perspective, Figure 2 illustrates the stockflow unemployment cycle in New Zealand from 1985:4 until 1994:3 It is the period-by-period expression of equation 2 and shows the shock-plateau-shock cycle that has characterised New Zealand's recent unemployment experience. (See Silverstone and Daldy 1993 for further

Figure 1. Gross flows between labour market states

New Zealand, all ages, males and females, quarterly average 1993:3-1994:3

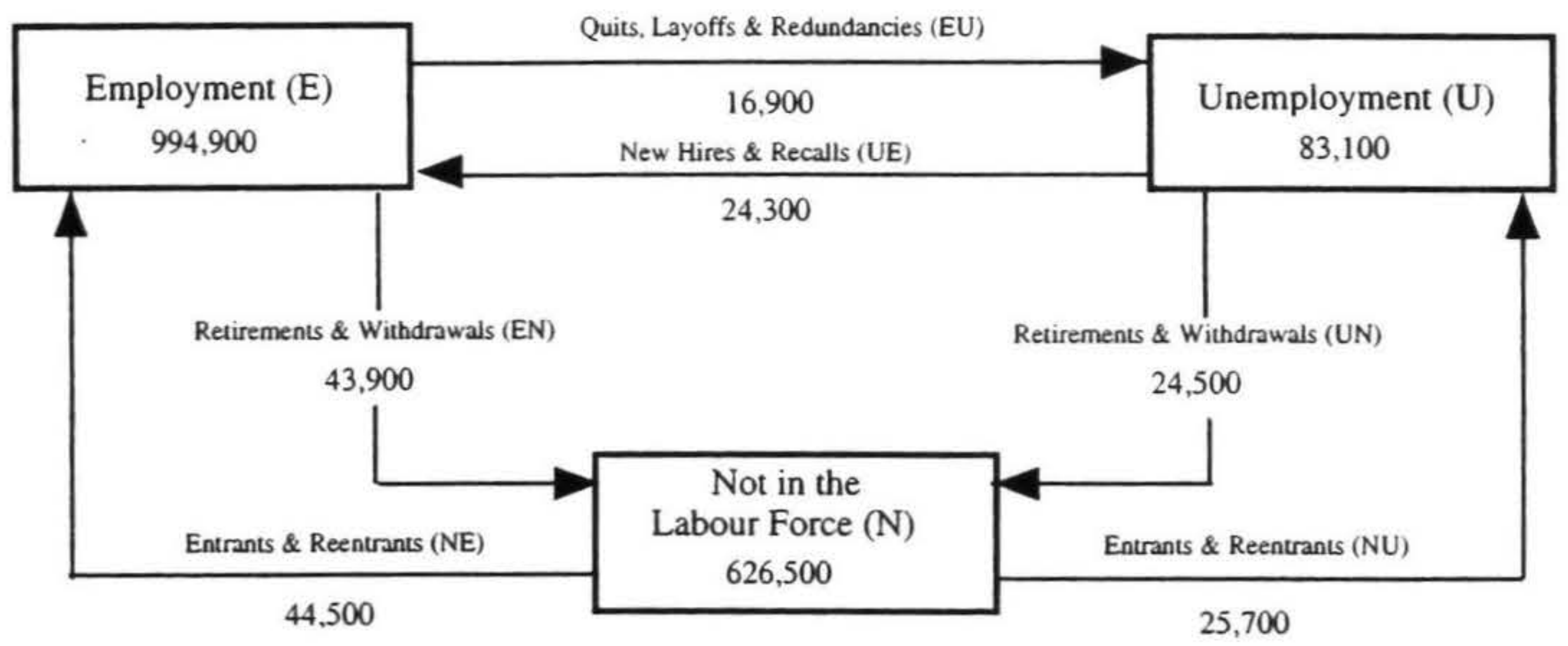

Source: Silverstone (1993) and Table 2 


\section{Figure 2. Unemployment stocks and flows}

New Zealand, all ages, males and females, quarterly 1985:4-1994:3

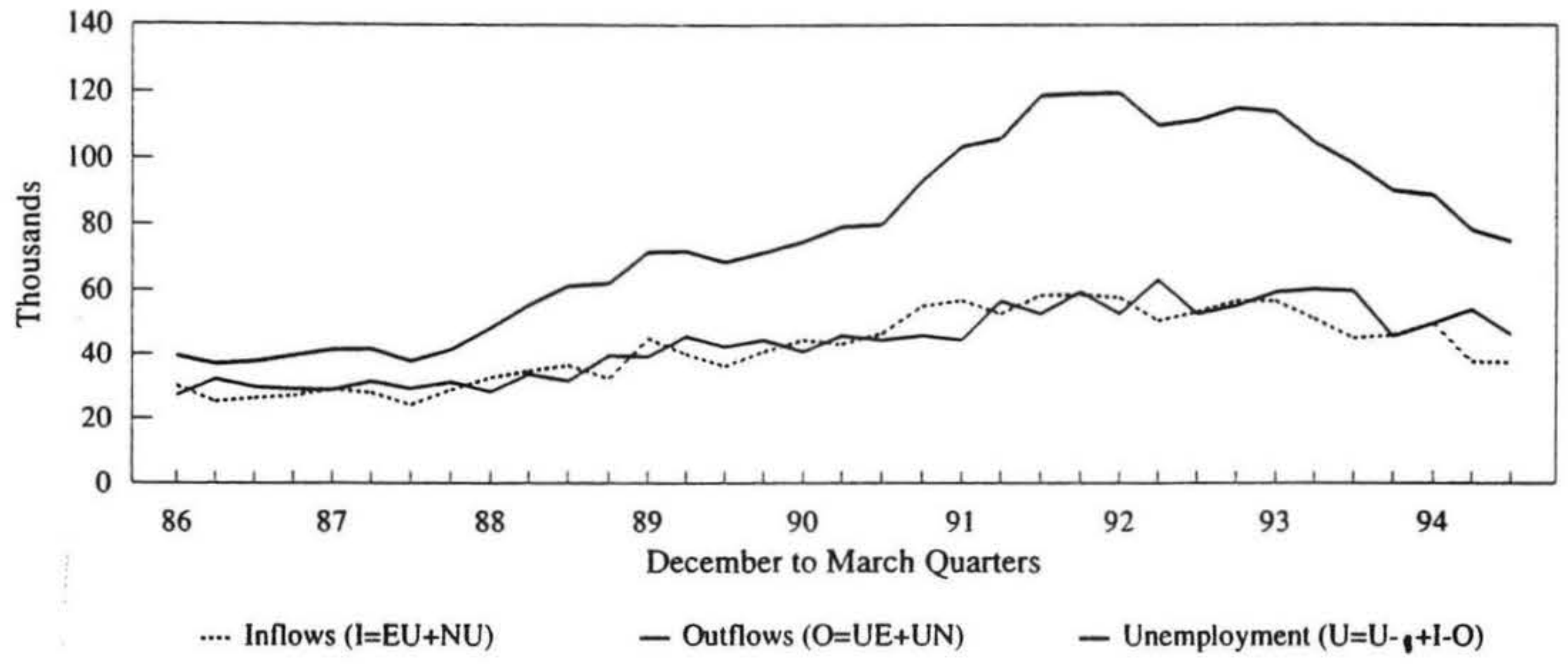

Source: Statistics New Zealand, HLFS Gross Flows.

details). Figure 2 also illustrates the significant impact on unemployment - sometimes favourable and sometimes unfavourable - of seemingly small changes in inflows and outflows. That is, a series of relatively small changes in the flows in one direction seem to initiate persistence in unemployment, sometimes upwards and sometimes downwards. The implication of this observation is that developments which cause unemployment outflows to dominate inflows, even by a relatively small amount, appear to have favourable 'high powered' effects on total unemployment, and conversely.
Finally, in this section, Figure 3 shows quarterly inflow and outflow rates to and from unemployment in New Zealand from 1985 to 1994 . The inflow rate is the ratio of arrivals into unemployment (EU $+\mathrm{NU})$ to the previous quarter's employment $\left(E_{-1}\right)$, while the outflow rate is the ratio of departures from unemployment (UE + UN) to the previous quarter's unemployment $\left(U_{-1}\right)$. Figures 3 reveals that the rise in unemployment to 1991 was due to a combination of a rising inflow rate and a falling outflow rate. Since 1991, the inflow rate to unemployment has declined while the outflow rate has strengthened. Both rates are now back to their 1989 values. One implication

Figure 3. Unemployment inflow and outflow rates

New Zealand, all ages, males and females, quarterly 1985:4-1994:3

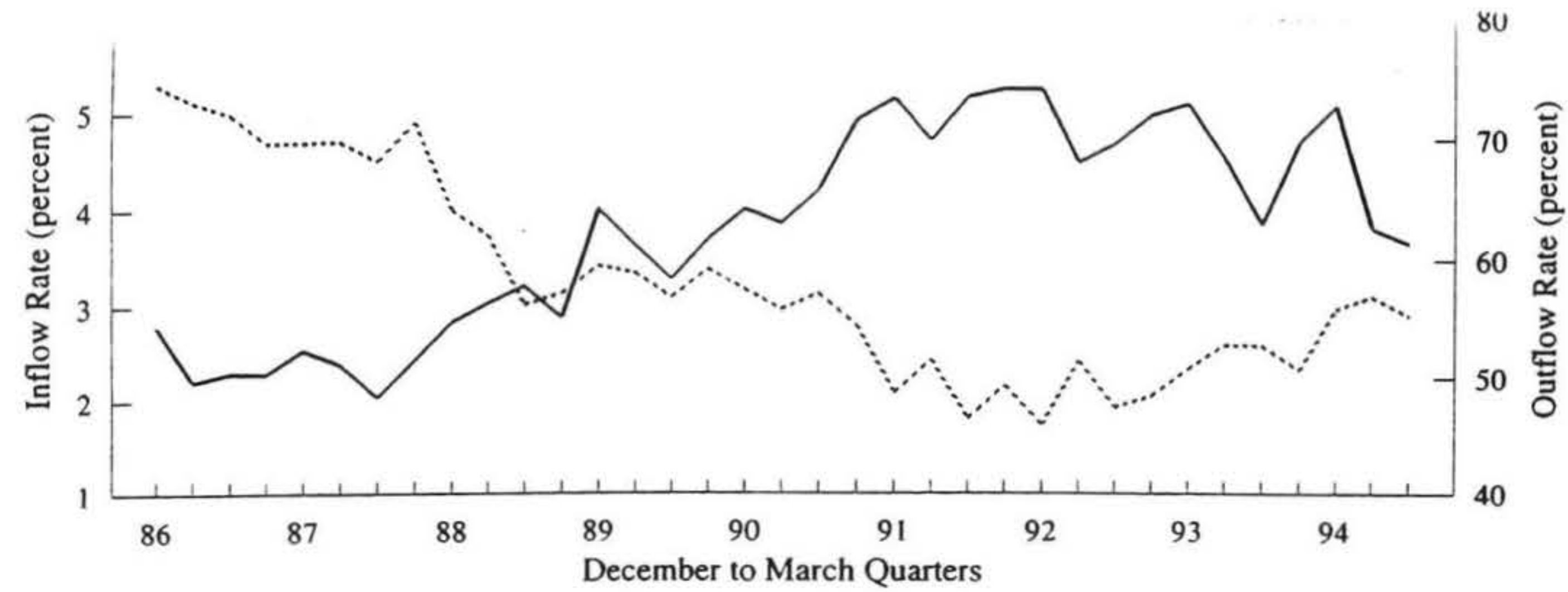

— Inflow Rate $(\mathrm{EU}+\mathrm{NU}) / \mathrm{E}-1 \quad$.... Outflow Rate $(\mathrm{UE}+\mathrm{UN}) / \mathrm{U}-1$

Source: Statistics New Zealand, HLFS Gross Flows. 


\begin{tabular}{|c|c|c|c|c|}
\hline \multirow{2}{*}{$\begin{array}{l}\text { Labour Force Status } \\
\text { in Previous Quarter }\end{array}$} & \multicolumn{3}{|c|}{ Labour Force Status in Current Quarter } & \multirow[b]{2}{*}{ Tota } \\
\hline & E & $\mathrm{U}$ & $\mathbf{N}$ & \\
\hline $\mathrm{E}_{-1}$ & 93.9 & 1.7 & 4.4 & 100 \\
\hline $\mathrm{U}_{-1}$ & 27.2 & 45.4 & 27.4 & 100 \\
\hline$N_{-1}$ & 7.1 & 4.1 & 88.8 & 100 \\
\hline
\end{tabular}

Source: Table 2 and Equation 3.

of these observations is that an understanding of the causes of unemployment in New Zealand might be enhanced if the determinants of our unemployment inflow and outflow rates could be found. (See Harris and Silverstone 1994 for a preliminary flow model of unemployment in New Zealand).

\section{Gross flow rates}

Because the gross flows data (in Tables 2) reflects movements between labour market states, flow rates between states can be calculated. The flow rate between, say, employment and unemployment (eu) is the average probability of a person moving from employment in the previous period to unemployment in the current period. It is calculated as the ratio of the current period's flow into unemployment (EU) to the employment stock in the previous period ((EE+EU+EN) or $\left.\mathrm{E}_{-1}\right)$. That is, eu - and similarly for the remaining flows - is equal to:

$$
\begin{aligned}
\mathrm{eu} & =\mathrm{EU} /(\mathrm{EE}+\mathrm{EU}+\mathrm{EN})=\mathrm{EU} / \mathrm{E}_{-1} \\
& =16.9 / 986.9 \\
& =0.0171 \text { or } 1.7 \% \text { (for } 1993 / 94)
\end{aligned}
$$

Table 3, then, is a matrix of the flow rates, or transition probabilities, corresponding to Table 2 and calculated using equation 3 . The cross diagonal entries represent ongoing employment, unemployment and nonparticipation, respectively. Overwhelmingly, those who were either employed or not in the labour force continue in this state between quarters. For the year ended September 1994, 94 percent of those who were employed in the previous quarter were employed in the current quarter while 89 percent of nonparticipants remained in that state. Alternatively, just six percent left employment each quarter, while 11 percent of nonparticipants joined the labour force each quarter. The situation is very different for the unemployed. On average, during 1993/94, for every 100 people unemployed in the previous quarter, 27 had found employment in the following quarter, 28 had left the labour force while 45 remained unemployed. Overall, Table 3 further highlights the dynamic character of New Zealand's labour market and unemployment movements in particular.

\section{Cycles}

While it appears initially more difficult to work with flow rates (Table 3) rather than with flow levels (Tables 1 and 2 ), flow rate information is usually more helpful in understanding labour market dynamics. This may be seen in Figure 4 which is a time series perspective of New Zealand's labour market flow rates from 1985:4 until 1994:3. It is the quarter-by-quarter representation of the nine elements in Table 3. Immediate observations, across most of the flow rates, include the favourable 1991/92 turning point and the presence of seasonality.

Several insights into New Zealand's unemployment behaviour are highlighted in these charts. First, the 'retention rate' into continuing unemployment (uu) has fallen from a peak of over 50 percent in 1991/92 to around 45 percent currently. Secondly, contrary to the conventional wisdom regarding the 'discouraged worker' effect, there was a decline in the flow rate from unemployment to not in the labour force (un) during the recessionary period up to 1992. Similarly, during the same recessionary period, there was an increase in the 'added worker' flow rate (nu) from not-in-the-labour-force to unemployment. Notwithstanding these brief insights into the discouraged and added worker effects, however, people in the category of 'not-in-the-labour-force' in New Zealand increased by 20 percent, or 150,000 people, between 1985 and 1994. Thirdly, it is noticeable that during the recent expansionary period, the flow rate from unemployment to employment (ue) has been checked by competition from the increased flow rate from nonparticipation to employment (ne). (See Keeley 1984 for a more detailed discussion).

In the remaining sections of this paper we use gross flows analysis to discuss briefly a selection of issues relating to steady state unemployment, gender and age differences and data bias. (See Grimmond 1993 for other illustrations including ethnic origin and qualifications). We begin with steady state unemployment.

\section{Steady state unemployment}

Flow rate data can be used to calculate a number of 'steady 

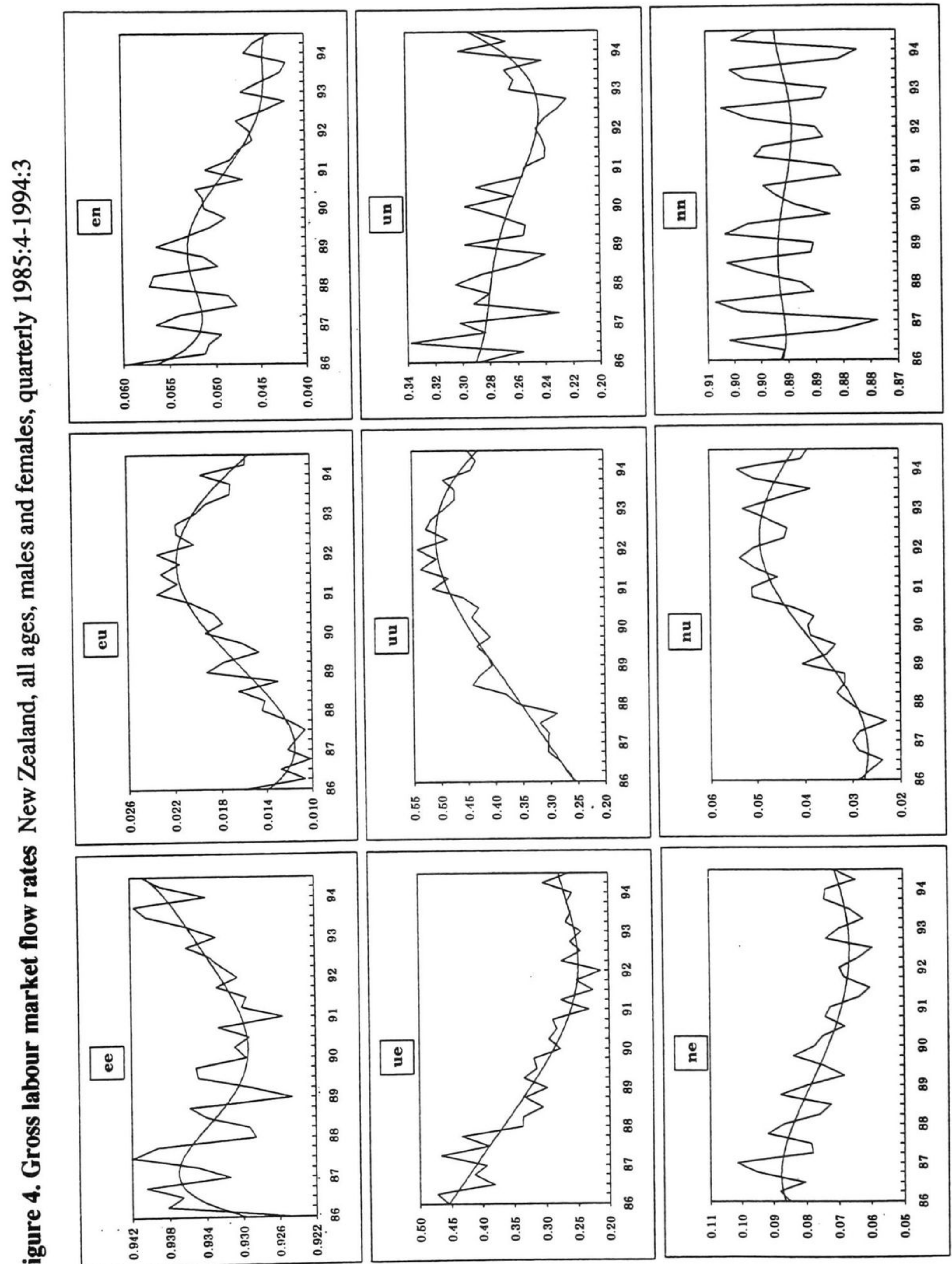
state' labour market outcomes for unemployment, participation, turnover and the duration of unemployment. (See Foster and Gregory 1984 for details). Take unemployment as an example. If the inflow rate into unemployment is equal to the outflow rate from unemployment, then the rate of unemployment itself will be unchanging; it will be in a steady state. Following Marston (1976) and Ehrenberg and Smith (1994), steady state unemployment is given by equation 5. This expression is derived from equation 4 where the left hand side of the upper equation represents the number of people who have entered unemployment. The right hand side represents the number of people who have left unemployment. A similar argument applies to the lower equation which represents flows to and from employment.

$$
\begin{aligned}
& (e u) E+(n u) N=(u e+u n) U \\
& (u e) U+(n e) N=(e u+e n) E
\end{aligned}
$$

Eliminating nonparticipation $(N)$ from these equations, and noting that the rate of unemployment is $U /(E+U)$, gives an expression for the steady state rate of unemployment, namely,

(5)

$$
u=\frac{}{1+\frac{(n e+n u) u e+(n e)(u n)}{(n e+n u) e u+(n u)(e n)}}
$$

Intuitively, the rate of unemployment in equation 5 depends on all six off-diagonal flow rates in Table 3 . Therefore, a lowering of the unemployment rate requires an increase the departure rates from unemployment (ue and un) and from nonparticipation (ne) or a decrease in the arrival rates into unemployment (eu and nu) and into nonparticipation (en). It should be recognised, though, that if a policy is directed specifically at changing one flow rate, it is unlikely that other flow rates will remain unchanged (Foster and Gregory 1984, p.117).

Using equation 5, and the data in Table 3, New Zealand's steady state unemployment rate averaged 6.9 percent for the year ended September 1994. The actual HLFS rate of unemployment, however, averaged 8.7 percent for the year ended September 1994. This is a significant difference in two series which should yield approximately the same answer. On a period-by-period basis - from 1985 to 1994 - the two series track each other reasonably closely. There is, however, is a tendency for the steady state unemployment rate to underestimate the HLFS rate especially during the current expansionary period. A possible explanation for this discrepancy is that the departure rates from unemployment to nonparticipation (un) and from nonparticipation to employment (ne) are exaggerated. This could be caused by classification error whereby people are recorded as having made a transition between labour market states when, in fact, no such movements have occurred. If this outcome is correct - and it raises the issue of cyclical bias in responses - it would cause the equilibrium unemployment rate to be lower than the actual rate. (See Keeley 1984 and Ritter 1993 for insights into the cyclical behaviour of American gross labour flows). The discrepancy between actual and gross unemployment rates also raises the more general issue of the extent to which 'unemployment' and 'not-in-the-labour-force' are distinct states.

\section{Gender differences}

Gross flows analysis provides some interesting insights into the cyclical differences between male and female unemployment rates. First, female behaviour, unlike male behaviour, appears to support the discouraged worker effect. That is, the probability of an unemployed female leaving the labour force rises during a recession and falls during a recovery. Hence, as the current recovery evolves, the gap between male and female unemployment rates presently favouring females - should diminish as females enter the unemployment pool in search of employment. Secondly, during the period from 1985 to 1994 , females were more mobile into and out of unemployment than males. This may be due partly to the rise in community, social and personal employment, where women dominate, compared to the fall in manufacturing and construction where men dominate.

\section{Age differences}

The likelihood of staying unemployed from quarter to quarter, or of leaving unemployment, has been largely similar across the three HLFS age groups ( 15 to 24,25 to 49 and over 49 years). The likelihood of moving into unemployment, however, is quite different across age groups. For example, by far the highest unemployment inflow rate is for those aged between 15 and 24 years of age. This rate has increased in absolute terms from just under 4 percent in mid 1986 to 10 percent in the early 1990 s.

The data on flow rates also indicates that young people, not unexpectedly, are far more mobile than the other age groups. They have the lowest probability of remaining in either employment or outside the labour force from quarter to quarter. Interestingly, the probability of a person over 49 years of age remaining in employment from quarter to quarter actually increased over the recessionary period. This may be explained partly by the gradual raising of the superannuation qualification age from 60 to 65 years.

Despite youth having the highest unemployment rate, currently an unemployed youth is, on average, more likely to find employment than people in other age categories. This has not always been the case. When the HLFS began in late 1985 , those aged 25 to 49 were most likely to find employment. This position changed in mid-1991. As a result, the probability of youth remaining unemployed has, during the present recovery, been lower and falling faster than the other age groups. The relative recovery in youth employment is centred in those sectors where youth are traditionally employed such as in the retail trade, restau- 
rants, hotels and in construction and manufacturing (especially fabricated metals).

\section{Data bias}

At least two major problems affect the accuracy of gross flows data, namely, rotation group error and classification error. Because of the HLFS's rotation pattern, the gross flows data will match only a proportion of the full sample survey. In principle, 87.5 percent of surveyed households should be matched between surveys. In practice, the level of matching has been consistently closer to 75 percent. This occurs because some people cannot be contacted or shift between quarters, or die or become 15 years of age between quarters. Woolf (1989, pp.34-35) finds that rotation group errors have had little effect on the match between the gross flows estimates of employment and the full sample survey estimates. The matched sample, though, consistently underestimates the number unemployed and overstates the number of people not in the labour force. Overall, and subject to some cautions with respect to measurement error, timing and weights, Woolf believes it is reasonable to assume that the characteristics of the persons in the unmatched sample are the same as those in the matched sample.

In addition to the potential bias generated by rotation group error, there is the potentially more serious bias caused by classification error. This is always a potential problem with panel data. With respect to gross flows panel data, classification error occurs when people are recorded as having made a transition between labour market states when, in fact, no such movement has occurred. This results in an overstatement of labour market flows in adjacent periods. Some attempts, especially in the United States and in Canada, have been made to adjust gross flows for missing observations and classification errors. The Abowd-Zellner adjusted series (based on reinterview responses and discussed in Blanchard and Diamond 1990) resulted in significantly reduced flows to and from American 'not-in-the labour-force' while leaving flows to and from employment and unemployment largely unaffected. Other research (for example, Meyer 1988) finds that the labour market is even less dynamic than the adjusted series suggest.

\section{Conclusions}

The United States gross flows series was once described as 'the neglected data base'. To some extent this comment applies to the New Zealand data as well. With few exceptions, announcements and commentaries on labour market conditions have tended to overlook the significant flows to and from employment, unemployment and nonparticipation. A major exception is the tendency to note significant job losses without noting the equally significant, but often widely spread, job gains. Although the net change in the size of New Zealand's various labour market stocks is relatively small between quarters, the ongoing dynamics of the labour market generate gross labour flows and flow rates on a scale that is not widely known.

Several conclusions have emerged from our study. First, aggregating across males, females and ages, New Zealand data implies a rapid turnover for about half of those who enter unemployment. One policy implication here is the need to accurately separate the 'at risk' group of new entrants to unemployment (to prevent their entry into the intractably difficult long-term group) from those who appear to require little intervention. Gross flows data may be able to assist in this task. Secondly, the flows data also highlights significant movements to and from 'not-in-thelabour-force' relative to movements between employment and unemployment. Thirdly, prior to 1991 , adverse movements in both unemployment inflow and outflow rates contributed to the rise in unemployment in New Zealand. Fourthly, the concept of steady state magnitudes gives some insight into key labour market characteristics while gender and age differences remind us of the heterogeneity of the labour market. Finally, data bias diminishes the reliability of the information from gross labour market flows.

\section{Further research}

In our opinion, the highest priority for further research relates to the reconciliation and possible adjustment of the gross flows series. The reconciliation exercise would involve matching the HLFS series on employment, unemployment and not in the labour force with the equivalent HLFS gross flows series. The adjustment exercise would involve the possibility of correcting the existing flows series for biases generated by classification errors and missing observations. Further tasks include the detection of the cyclical and seasonal properties in the gross flows series, the econometric modelling of unemployment inflows and outflows and research to determine whether unemployment and 'not in the labour force' are distinct states.

\section{Note}

This paper was supported by Grant Z582 from the University of Waikato Research Committee. The authors are grateful for this support.

\section{References}

Blanchard, Olivier J. and Peter Diamond 1990 The cyclical behavior of the gross flows of U.S. workers Brookings Papers on Economic Activity (2):85155.

Burda, Michael and Charles Wyplosz 1994 Gross worker and job flows in Europe European Economic Review 38(6):1287-1315.

Ehrenberg Ronald G. and Robert S. Smith 1994 Modern labor economics New York: Harper Collins. 
Foster, W.F and R.G. Gregory 1984 A flow analysis of the labour market in Australia. In R. Blandy and O. Covick (eds) Understanding labour markets in Australia Sydney Allen and Unwin.

Grimmond, David 1993 Labour force dynamics in New Zealand: a preliminary analysis NZIER Research Monograph 60.

Harris, Richard and Brian Silverstone 1994 A flows model of unemployment in New Zealand Paper presented at a conference of the New Zealand Association of Economists Massey University Palmerston North.

Keeley, Michael C. 1984 Cyclical unemployment and employment: effects of labor force entry and exit Federal Reserve Bank of San Francisco Economic Review (3):5-25.

Marston, Stephen T. 1976 Employment instability and high unemployment rates Brookings Papers on Economic Activity (1):169-203.

Meyer, Bruce D. 1988 Classification-error models and labor-market dynamics Journal of Business and Economic Statistics 6(3):385-90.

Ritter, Joseph A. 1993 Measuring labor market dynamics: gross flows of workers and jobs Federal Reserve Bank of St Louis Review 75(6):39-57.

Silverstone, Brian 1993 Labour market flows in New Zealand Waikato Regional Economic Bulletin (2):913.

Silverstone, Brian and Bridget Daldy 1993 Recent unemployment and industrial relations experience in New Zealand Australian Economic Review (4):1117.

Woolf, Julie 1989 Gross flows estimates from the household labour force survey New Zealand Labour Force (3):32-42.

\section{Authors}

Brian Silverstone is a Senior Lecturer in Economics at the University of Waikato, Private Bag 3105, Hamilton. Susi Gorbey is an Assistant Research Economist at the New Zealand Institute of Economic Research, PO Box 3479, Wellington. 